Fủr foldhe, Denen eine berartige Unterweifung fefit, alfo für forftlidje Raien, gleidit dajpelfe einem jđarfen $\mathfrak{M e f f e r}$ in Der Sgand eines SinDes!

(58 würde ein aนtżgezeidynetes fein, wenn es wentger einfeitig wåre. Biel(eid)t findet Der Berfaffer ez angemeffen, fpätere

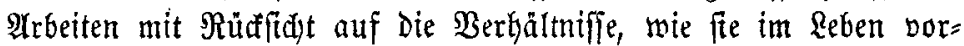

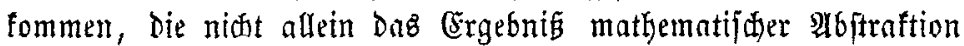
find, fu behandeln, biedurdy würde er fein Điublifun nidyt nur melyr befriedigen, fondern ihm inģge ammt mehgr nüken.

BBir haben unjer $\mathfrak{u}$ rtheil hier unbefangen abgegeben, da eg

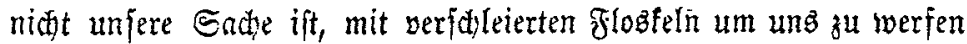
und allenthalben unz Şinterthürer: offen zu halten. M̉enn wir audi) glauten, Damit in ein oder das andere $\mathfrak{B s e f p e m e f t}$ geftodien zu baben, geten wir uns Dod Der Soffinung hin, Dá gerade Der Berfaffer fich ninft verleģt fühlen twird, Deffent Berbienft int feinem Berufe wir ebenjo unbedingt anerfennen, als wir glauben in Dem unjrigen zu Saauje zu jein.

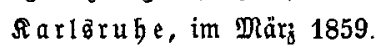

\title{
7. Dengler.
}

\section{Эagjuefer.}

Der $\mathfrak{B a f i j a r b}$ auf ber Fafamenjagd.

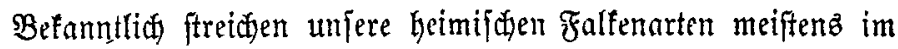
Tsinter fort, biz auf dén Butiard (falco buteo), der fít) Gejonderz Dann in bie Brühter und Eümpfe zieht, wo bet Wintertreibjagden

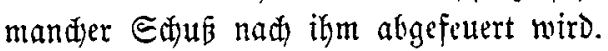

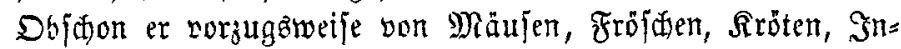

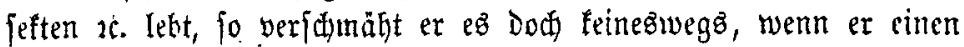
Sajen, ein Felobugn oder ferbit einen zrojanen befommen fann, weldhe er nidyt nur auf Dem anftanbe, alz feitrer Rleblingziongd, jondern auty auf Dem \$ürfignng - \$arforçe= ober Selbingden fann er allerbings niđjt mit Erfolg halten — zu beformen weis.

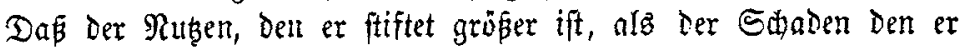




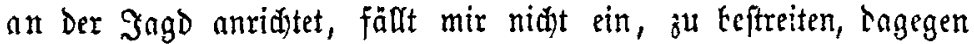

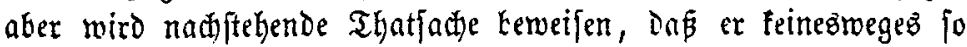
gang un[đädliđ ift, wie man mitunter befiaupten bört.

$\mathfrak{A} \mathfrak{m}$ 25. Iejember v. S. gegen Mittag, ging ein erfahrener, ftetz aufmerfjamer und zuverläßiger Jagdhüter von bier in Die

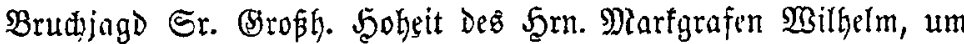

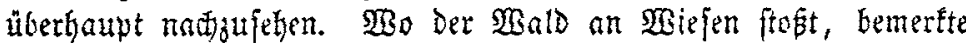
er auf Diefen am Traufe zroei Fafanen, an Die er fith bom $\mathfrak{B a r d}$ her in einem alten Braben anzuldteidten futtse, um jut fehen, ob

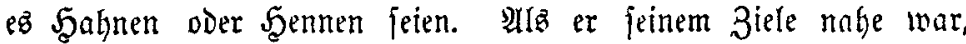
ftriđ, von einem jungen $\mathcal{E}_{\text {allage }}$ kerfommend, ein grofer $\mathfrak{B}$ ogel an ihm vorbei und auf Den Drt fu, wo tie Fafanen waren, Den er,

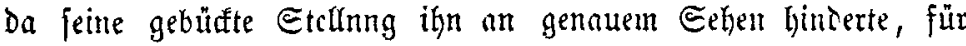
einen zafanen bielt, bon iem er glaufte, er frathe die 2 Frajanen

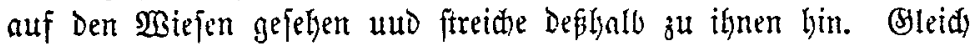
Darauf vernakim er gang eigenthümlidje Töne und ein ftarfez (s)e=

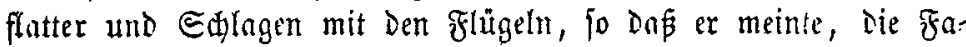
fanen fämpften miteinander. $\mathfrak{U}_{\mathfrak{m}}$ in's Reine ju fommen, rimtete er fid auf, wo er Damt bu feinem Erftaunen gewahrte, Dak Der Ginģugeflogene bermeintliçe Fajan ein Raubrogel war, Dor Den einen Fajanen gefangen hatte und diefen fefthaltend mit ifm herum=

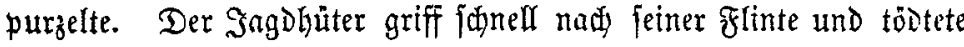
auf einen Єđü Den Fajanentahn, Der von feinem Begner jtarf vertwundet war und diefen felbft, weld Seb̧terer ein leibfaftiger Burfard ift. Do Der Buffard die Fafanen von Ferne gefefen und

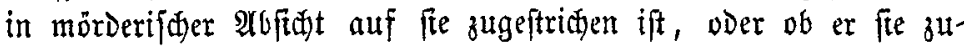
fällig traf und fojufagen nur im Borbeigefen einen mitnehmen wollte, ift freilich unbeftimmt; Das Erffere hat Defigalb viel Blaub= murdigfeit, weil ber Buffard die auf Den Biefen herumgelaufenten Fajanen bon wseitem jehen fonnte.

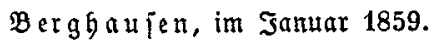

\$̧ตmer.

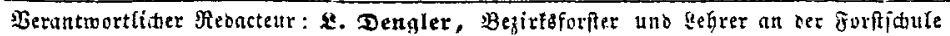

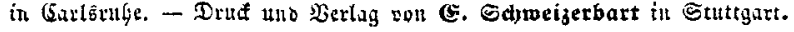

